\title{
RESEARCH ON THE HEAVY METALS IN SURFACE SEDIMENTS, IN STRÂMTORI-FIRIZA RESERVOIR, SITUATED IN N-W OF ROMANIA
}

\author{
IRINA SMICAL ${ }^{\mathrm{a},{ }^{*}}$, ADRIANA MUNTEAN ${ }^{\mathrm{b}}$, DAN CIURTE ${ }^{\mathrm{b}}$, VALER MICLE $^{\mathrm{c}}$
}

\begin{abstract}
In this study referring to the surface sediments quality of Strâmtori-Firiza reservoir, a series of heavy metals like arsenic, cadmium, copper, lead and zinc were investigated from 2017 to 2019. The samples analysis and interpretation of the results for 18 samples taken from surface sediments indicated that the correlation coefficients calculated for the metallic elements showed a significant correlation between them. Thus, highlighting their same origin in the composition of the studied surface sediments, only the value of the coefficient between $\mathrm{As}$ and $\mathrm{Pb}$ implies a statistically significant correlation. Pollution indices, calculated for each sampling site, indicated anthropogenic unpolluted surface sediments. The potential ecological risk (RI), calculated for assessing the toxicity risk related to surface benthic biomass, showed that the potential ecological risk for biological life in surface sediments was low.
\end{abstract}

Keywords: surface sediment, heavy metals, risk, pollution indices

\section{INTRODUCTION}

The development of the non-ferrous ore exploitation and processing industry between 1950s and 1960s in Baia Mare area, coupled with the migration of the labor force from the villages to the city, led to the review of water needs and the design of engineering schemes for hydro-technical planning [1]. At the Somes-Tisa basin, this planning management water

\footnotetext{
a North University Centre of Baia Mare, Technical University of Cluj-Napoca, Engineering of Mineral Resources, Materials and Environment Department, 62A Victor Babes str., 430083, Baia Mare, Romania

b Maramureș Water Management System, Someș-Tisa Basinal Water Administration, no. 2, Hortensiei Street, 430294, Baia Mare, Romania

c Technical University of Cluj-Napoca, Faculty of Materials and Environmental Engineering, 28, Memorandumului Street, 400114 Cluj-Napoca, Romania

*Corresponding author: irina.smical@cunbm.utcluj.ro
} 
needs includes, after the main use - the drinking water supply of the localities, other uses as: raw water for industry, hydropower potential, flood protection, irrigation, fishing and even recreational activities.

In this context, during the period 1960-1964, the works for the construction of the Strâmtori reservoir on the Firiza River and the Berdu compensatory lake were executed, which had as main use the supply of raw water for industry, as well as drinking water for the downstream population. The energy potential of the dam is also used, with an installed power of 4.2 MW [1].

The Strâmtori accumulation is located on the Firiza River, about $10 \mathrm{~km}$ upstream of Baia Mare. The accumulation dam is built in concrete counterweight, with a useful volume (at commissioning in 1964) of 14.5 million $\mathrm{m}^{3}$, the annual average clogging being less than $20000 \mathrm{~m}^{3}$, holding a reception pool with an area of $130 \mathrm{~km}^{2}[1-2]$.

After 1997, when the mining activity was ceased, the Strâmtori-Firiza reservoir has served mainly for supplying of raw water for drinking in Baia Mare area.

Elaborated as a result of recent studies on the status of the caging of the reservoir [2], the present study highlights the current state of pollution with characteristic metals of the area: arsenic, cadmium, copper, lead and zinc, by analyzing the water, the surface sediment layer and calculating the pollution indices.

To assess the environmental risks associated with the heavy metals ( $\mathrm{Cr}, \mathrm{Mn}, \mathrm{Cu}, \mathrm{Zn}, \mathrm{Cd}, \mathrm{Hg}$ and $\mathrm{Pb}$ ) migration in sediments in various water reservoirs or accumulations, a lot of research has been made all over the world [3-7].

The influence of human activities like agriculture, waterborne transport, industry and especially mining industry was highlighted by Bing et al., (2016) [5] in their research regarding the heavy metal contamination of sediments of Three Gorges Reservoir (TGR) from China. More recently studies on heavy metal contamination of surface water of the Three Gorges Reservoir (TGR) showed that heavy metals did not exceed the first grade water quality threshold values, excepting $\mathrm{Zn}$. The main risk for human health was due to the presence of $\mathrm{Cr}$ and As [8].

The research of Pratap et al., (2020) [9] to assess the influence of wastewater discharging from Kinoya Wastewater Treatment Plant into Laucala Bay sediments, showed an important increase of the concentration of studied metals in the place around the discharging effluent sites. This indicated the negative anthropic influence on the sediments quality. The results of research made by Zhou et al., (2017) [10] for a drinking water reservoir in China showed an increasing of the organic carbon (OC), total nitrogen (TN), and total phosphorus (TP) in sediments. As well, the concentration of Fe and Mn posed high to very high risk [10]. 
RESEARCH ON THE HEAVY METALS IN SURFACE SEDIMENTS,

IN STRÂMTORI-FIRIZA RESERVOIR, SITUATED IN N-W OF ROMANIA

The aim of this study was to assess the surface sediments quality of Strâmtori-Firiza reservoir related to a series of heavy metals like arsenic, cadmium, copper, lead and zinc. For this, the following indices were calculated: (1) Single pollution index, (2) Geo-accumulation index, (3) Contamination factor, (4) Pollution Load Index and (5) Multi-element contamination.

\section{RESULTS AND DISCUSSION}

\section{Trace elements in water}

In the monitoring period (2017-2019) the obtained results for the investigated elements ( $\mathrm{As}, \mathrm{Cd}, \mathrm{Cu}, \mathrm{Pb}$ and $\mathrm{Zn}$ ) were compared with the maximum allowed concentrations, expressed as quality standards (QS) by the Romanian legislation [11] and the lake water was within the first class of quality, as shown in Table 1.

Table 1. Basic statistics of metal concentrations in water samples

\begin{tabular}{|c|c|c|c|c|c|}
\hline Metal & As & Cd & $\mathrm{Cu}$ & $\mathrm{Pb}$ & $\mathrm{Zn}$ \\
\hline${ }^{*} \mathrm{QS}, \mu \mathrm{g} \mathrm{L^{-1 }}$ & 10.000 & 0.500 & 20.000 & 5.000 & 100.000 \\
\hline \multicolumn{6}{|c|}{$\begin{array}{c}\text { Basic statistics of metal concentrations in } 18 \text { water samples collected from } \\
6 \text { locations, in } 3 \text { sampling campaigns during } 2017-2019 \text { period }\end{array}$} \\
\hline Minimum, $\mu \mathrm{g} \mathrm{L}^{-1}$ & 0.360 & 0.120 & 0.750 & 1.040 & 7.902 \\
\hline Maximum, $\mu g \mathrm{~L}^{-1}$ & 1.080 & 0.260 & 20.004 & 1.460 & 58.101 \\
\hline Average, $\mu g \mathrm{~L}^{-1}$ & 0.724 & 0.179 & 10.422 & 1.205 & 26.713 \\
\hline Standard deviation, $\mathrm{\mu g} \mathrm{I}^{-1}$ & 0.202 & 0.041 & 9.631 & 0.124 & 11.504 \\
\hline Detection limit, $\mu \mathrm{g}$ L-1 & 0.300 & 0.075 & 0.500 & 1.000 & 5.000 \\
\hline
\end{tabular}

\section{Trace elements in surface sediment}

Because there were no data for the natural background of sediments in this area, the obtained concentration values were compared with the quality standard (QS) values, provided by Romanian legislation as maximum allowed values [11].

As outlined in Table 2, no obtained value exceeded the maximum allowed values provided by Romanian normative [11]. Zn concentrations were approaching its corresponding QS (concentration determined as $89.33 \%$ of QS), in sampling campaign of 2019, in the sampling point 3. 
Table 2. Basic statistics of metal concentrations in 18 sediment samples collected from 6 locations, in 3 sampling campaigns, from 2017 to 2019

\begin{tabular}{|c|c|c|c|c|c|}
\hline Metal & $\begin{array}{c}{ }^{*} \mathrm{QS}, \\
\mathrm{mg} \mathrm{kg}{ }^{-1}, \\
\left({ }^{* *} \mathrm{~d} . \mathrm{w} .\right)\end{array}$ & $\begin{array}{c}\text { Minimum, } \\
\mathrm{mg} \mathrm{kg}^{-1}\end{array}$ & $\begin{array}{c}\text { Maximum, } \\
\mathrm{mg} \mathrm{kg}^{-1}\end{array}$ & $\begin{array}{c}\text { Average, } \\
\mathrm{mg} \mathrm{kg}^{-1}\end{array}$ & $\begin{array}{c}\text { Standard } \\
\text { deviation, } \\
\mathrm{mg} \mathrm{kg}^{-1}\end{array}$ \\
\hline $\mathbf{A s}$ & 29.000 & $\begin{array}{c}0.980 \\
\text { (in 2018, in P1) }\end{array}$ & $\begin{array}{c}3.670 \\
\text { (in 2019, in P3) }\end{array}$ & 2.001 & 0.761 \\
\hline $\mathbf{C d}$ & 0.800 & $\begin{array}{c}0.590 \\
\text { (in 2018, in P1) }\end{array}$ & $\begin{array}{c}1.650 \\
\text { (in 2018, in P3) }\end{array}$ & 0.990 & 0.261 \\
\hline $\mathbf{C u}$ & 40.000 & $\begin{array}{c}5.221 \\
\text { (in 2017, in P1) }\end{array}$ & $\begin{array}{c}34.103 \\
\text { (in 2018, in P3) }\end{array}$ & 16.402 & 7.903 \\
\hline $\mathbf{P b}$ & 85.000 & $\begin{array}{c}10.404 \\
\text { (in 2018, in P6) }\end{array}$ & $\begin{array}{c}35.201 \\
\text { (in 2019, in P3) }\end{array}$ & 19.172 & 6.264 \\
\hline $\mathbf{Z n}$ & 150.000 & $\begin{array}{c}51.504 \\
\text { (in 2018, in P1) }\end{array}$ & $\begin{array}{c}134.003 \\
\text { (in 2019, in P3) }\end{array}$ & 76.195 & 23.174 \\
\hline
\end{tabular}

* Quality Standards (QS) for the elements, according to the Romanian legislation for sediments, fraction $<63 \mu \mathrm{m}$ [11]

${ }^{* *}$ dry weight

Although the correlation coefficients calculated for the studied metals showed a good correlation between them, thus highlighting their same origin in the composition of the studied surface sediments, only the value of the correlation coefficient between $\mathrm{As}$ and $\mathrm{Pb}$ implied a statistically significant correlation (Table 3).

Table 3. Correlation coefficients between heavy metals analyzed form surface sediment

\begin{tabular}{|l|c|c|c|c|c|}
\hline & As & $\mathbf{C d}$ & $\mathbf{C u}$ & $\mathbf{P b}$ & $\mathbf{Z n}$ \\
\hline $\mathbf{A s}$ & 1.000 & & & & \\
\hline $\mathbf{C d}$ & 0.822 & 1.000 & & & \\
\hline $\mathrm{Cu}$ & 0.870 & 0.840 & 1.000 & & \\
\hline $\mathbf{P b}$ & $0.891^{*}$ & 0.712 & 0.869 & 1.000 & \\
\hline $\mathbf{Z n}$ & 0.773 & 0.861 & 0.734 & 0.679 & 1.000 \\
\hline \multicolumn{6}{|c}{ significant correlation (the critical value for $\mathbf{p}=\mathbf{5 \%}$ is $\mathbf{0 . 8 8 0}$} \\
\hline
\end{tabular}

The Single Pollution Index was calculated with the mean of all obtained values in the sampling campaigns and was presented in Table 2. According to values of the Single Pollution Index in Figure 1, the level of contamination 
for each site and metal was established (Figure 1). The results for the sampling sites do not show any contamination with $\mathrm{As}, \mathrm{Cu}, \mathrm{Pb}$ and $\mathrm{Zn}$. There was one exception for $\mathrm{Cd}$, for which the calculated pollution index showed a low pollution in P1, P2, P3, P4, P5 and P6 sampling sites.

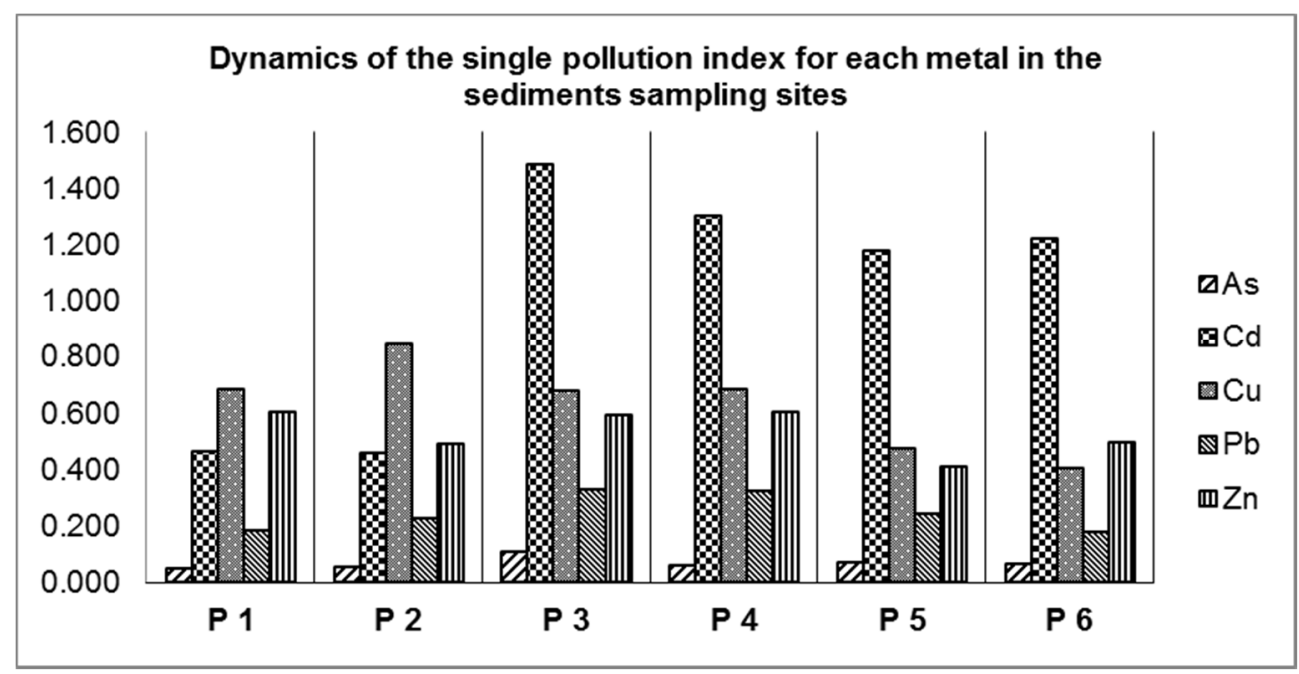

Figure 1. Single pollution Index for each metal from sediments in the 6 sampling sites

The maximum value of the pollution index (1.488) was calculated in P3 sampling site, closest to the potential anthropic impact. Also, the calculated PLI indicated a low pollution of the surface sediments with Cd in all sites, through accumulation in the surface sediment layer, most likely, due to various anthropic activities (upstream urban agglomerations or relaxing activities allowed near the lake perimeter).

The obtained values for the geo-accumulation index - Table 4 reflect the non-pollution of the area, from the point of view of the studied elements.

Table 4. Basic statistic of the $\lg _{g a}$

\begin{tabular}{|l|c|c|c|}
\hline Iga & Minimum & Maximum & Mean \\
\hline $\mathbf{A s}$ & -3.957 & -2.858 & -3.593 \\
\hline $\mathbf{C d}$ & -0.936 & -0.401 & -0.645 \\
\hline $\mathbf{C u}$ & -3.618 & -1.489 & -2.370 \\
\hline $\mathbf{P b}$ & -1.464 & -0.543 & -1.149 \\
\hline $\mathbf{Z n}$ & -1.887 & -1.325 & -1.663 \\
\hline
\end{tabular}


The contamination factor, calculated with equation 3 , shows the moderate contamination with cadmium, mostly in the P3 sampling point, where the single pollution index also indicated a slight pollution (Figure 2).

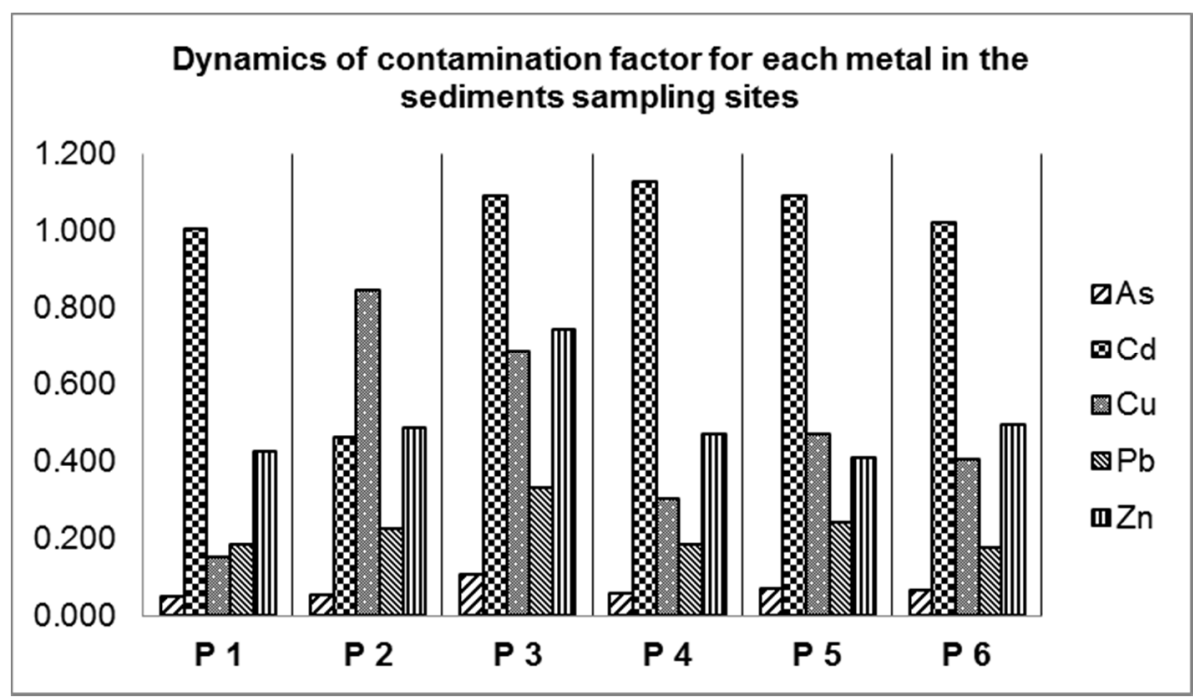

Figure 2. Dynamics of the contamination factor for each metal

The sum of the contamination factors calculated for each sampling site, allowed to highlight the degree of contamination corresponding to the entire studied area, for each investigated metal: $A s=0.793 ; C d=5.94$; $\mathrm{Cu}=1.97 ; \mathrm{Pb}=1.64 ; \mathrm{Zn}=2.91$. In accordance with the values, it can be concluded that the surface sediments in this area are not contaminated with $\mathrm{As}, \mathrm{Cd}, \mathrm{Cu}, \mathrm{Pb}$ or $\mathrm{Zn}$, and the global degree of contamination was low.

To evaluate the total degree of contamination due to the accumulation of heavy metals in surface sediments the pollution load Index $(P L I)=0.328$ was calculated. The obtained value indicated non-pollution of the study area.

The source of heavy metals was identified after calculating the multielement contamination index (MEC), in accordance to equation 5 . The value of the $\mathrm{MEC}=0.428$, certifies that there was not anthropogenic impact on the analyzed surface sediments of the reservoir Strâmtori-Firiza.

The potential ecological risk (RI) was also calculated for assessing the toxicity risk related at surface benthonic biomass, in accordance with equations 6 and $7(\mathrm{RI}=43.7)$. The result showed that the potential ecological risk for biological life in surface sediments was low. 


\section{CONCLUSIONS}

In accordance with the results obtained during the entire monitoring period it could be said that the correlation factors calculated for the studied metals, indicated a direct connection and distinctly significant correlations factor between $\mathrm{As}$ and $\mathrm{Pb}$. This is due to the same provenience of the metals from non-ferrous ores. Correlation factors between $\mathrm{Pb}$ and $\mathrm{Cd}, \mathrm{Zn}$ and $\mathrm{As}$, $\mathrm{Zn}$ and $\mathrm{Cu}$, or $\mathrm{Zn}$ and $\mathrm{Pb}$ were calculated, without statistically importance. As a consequence, the pollution indices calculated for each sampling site indicated unpolluted anthropic surface sediment.

There was highlighted an absent level of pollution with $\mathrm{As}, \mathrm{Cu}, \mathrm{Pb}$ and $\mathrm{Zn}$; except for $\mathrm{Cd}$, for which the calculated pollution index showed a low pollution in P1, P2, P3, P4, P5 and P6 sampling sites.

A low pollution of the surface sediments with $\mathrm{Cd}$ was determined in all sites, through accumulation in the surface sediment layer, most likely, due to anthropic activities.

The source of heavy metals, identified after calculating the multielement contamination index (MEC), indicated that there was not anthropogenic impact on the analyzed surface sediments of the reservoir Stramtori-Firiza.

The potential ecological risk (RI) calculated for assessing the toxicity risk related at surface benthonic biomass showed that the potential ecological risk for biological life in surface sediments was low.

\section{EXPERIMENTAL SECTION}

In the studied period 2017-2019, the sampling campaigns started at 15 th of June, depending on climatic conditions. Also, the sampling sections of water and surface sediment were the same in each investigated year. Studied area is shown in Figure 3.

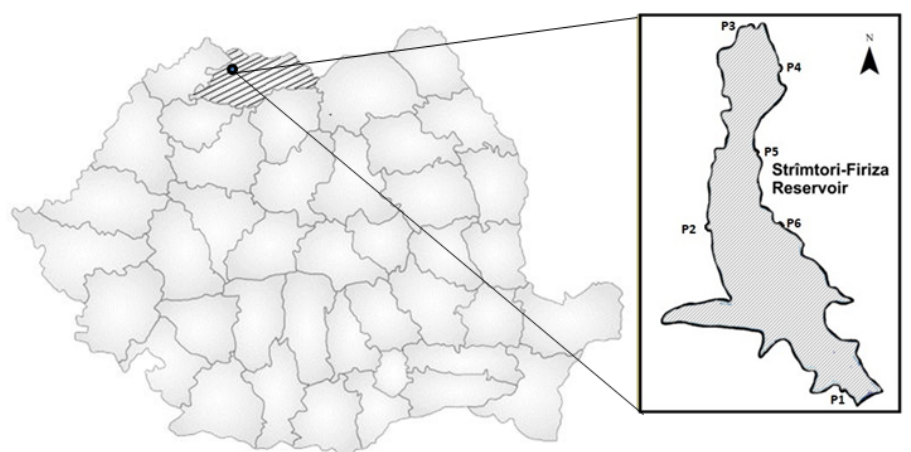

Figure 3. Sampling points on the Strâmtori-Firiza reservoir 


\section{Sampling and conservation the samples}

In the studied period of time (2017-2019), the sampling campaigns were held in June, after 15th, depending on climatic conditions. Both the sampling sections of water and surface sediment were the same in each investigated year.

Water sampling was carried out from the foothills of the lake, in 6 sites, using a $1.5 \mathrm{~m}$ long telescopic rod, with a $1 \mathrm{~L}$ plastic container. From each sampling point, three samples were collected, then they were homogenized in a bucket, from which a $1 \mathrm{~L}$ sample was collected in a glass container. The water samples thus obtained were preserved with $\mathrm{HNO} 3$ (65\%, p.a., Merck, Darmstadt, Germany) [12]) and transported to the laboratory.

For surface sediment sampling, a Draga-Ponar sampler was used; from each of the 6 sampling points. Three independent replicates were collected, which constituted, after homogenization, the sample from that sampling point. For the present study, the sieving of the collected sediment samples was performed in order to collect the sediment fraction $<63 \mu \mathrm{m}$, in wet environment, immediately after sampling $[13,14]$. The sediment fractions $(<63 \mu \mathrm{m})$, each of at least $50 \mathrm{~g}$, were collected in glass containers, transported in the laboratory and air-dried (far from the direct sun rays). After the complete drying (about 2 days) to the constant mass the part of it, $0.2 \mathrm{~g}$ of sediment, applying the quartering method, was subjected to the mineralization, in order to determine the concentrations of metals [15].

The concentrations of heavy metals in water samples were interpreted in accordance with Romanian legislation in force [11], for the first class of quality.

In order to assess the heavy metals pollution of surface sediment, different indices were used [16-20].

Single Pollution Index (PI) - used in order to provide a measure of the contamination degree of the sampling site with individual studied element. Pollution Index was calculated using the equation 1 [20]:

$$
P l_{i}=\frac{C_{i}}{S_{i}}
$$

where: $P l_{i}$ - pollution index for metal $i ; C_{i}$ - mean concentration of metal in surface sediment; $S_{i}$-references values, provided by national legislation, as ca maximum allowed values [11].

Geo-accumulation index $\left(\mathbf{I}_{\mathrm{ga}}\right)$ - used to complete the previous data and information to establish the pollution degree [21] and then other researchers calculated the geo-accumulation index [16-17] [21-23] using equation 2: 


$$
I_{g a}=\log _{2}\left(\frac{C_{n}}{K \times C_{f n}}\right)
$$

where: $I_{g a}$ - geo-accumulation index; $C_{n}$ - the $\mathrm{n}$ element concentration in $0.63 \mu \mathrm{m}$ sediment fraction; $K$ - correction factor for element required by the geochemical background and lithological conditions variation, $K=1.5 ; C_{f n}-$ natural geochemical background of the $n$ element in sediment ( $A s=15$; $\mathrm{Cd}=1.0 ; \mathrm{Cu}=50 ; \mathrm{Pb}=70 ; \mathrm{Zn}=175$, all expressed in $\mathrm{mg} \mathrm{kg}^{-1}$ dry weight) [20].

The obtained results for the two indices were compared with the values shown in Table 5 .

Table 5. Assessment of the potential ecological risk with pollution indices

\begin{tabular}{|c|l|c|l|}
\hline \multicolumn{2}{|c|}{$\begin{array}{c}\text { Single Pollution index (PI) } \\
\text { highlights the contamination level }\end{array}$} & \multicolumn{2}{c|}{$\begin{array}{c}\text { Geo-accumulation index }\left(I_{g a}\right)^{*} \\
\text { highlights the pollution degree }\end{array}$} \\
\hline $\mathrm{PI} \leq 1$ & absent & $\leq 0$ & unpolluted \\
\hline $1<\mathrm{Pl}<2$ & low & $0-1$ & unpolluted to moderately \\
\hline $2<\mathrm{Pl}<3$ & moderate & $1-2$ & moderately \\
\hline $3<\mathrm{PI}<5$ & strong & $2-3$ & moderately to highly \\
\hline $\mathrm{PI}>5$ & very strong & $3-4$ & highly \\
\hline \multirow{3}{*}{$*$} & $4-5$ & highly to extremely high \\
\cline { 2 - 4 } & $>5$ & extremely high \\
\cline { 3 - 4 } & &
\end{tabular}

Contamination factor $\left(\mathbf{C}_{\mathrm{f}}\right)$ - illustrates the difference between sample and reference values of each heavy metal. It is calculated with equation 3 [20]:

$$
C_{f}=\frac{C_{m}}{C_{p-i}} \times C_{f}
$$

where:

$C_{m}$ - mean of content of the heavy metal, of the individual sampling point, in $\mathrm{mg} \mathrm{kg}^{-1}$;

$C_{p-i}$ - pre-industrial reference value for the heavy metals [20].

The sum of the contamination factors for the each metal, illustrated de degree of contamination. The contamination factor and the degree contamination were interpreted according to the values provided in Table 6 [16]. 
Table 6. Contamination Factor $\left(\mathrm{C}_{f}\right)$ and Degree of Contamination $\left(\mathrm{C}_{\mathrm{deg}}\right)$ interpretation (Kowalska et al., 2018 [16])

\begin{tabular}{|c|c|c|c|}
\hline $\boldsymbol{C}_{\boldsymbol{f}}$ value & Contamination & $\boldsymbol{C}_{\boldsymbol{d e g}}$ value & Degree of contamination \\
\hline$<1$ & low & $<8$ & low \\
\hline $1-3$ & moderate & $8-16$ & moderate \\
\hline $3-6$ & considerable & $16-32$ & considerable \\
\hline$>6$ & very high & $>32$ & very high \\
\hline
\end{tabular}

The degree of total pollution was evaluated with the Pollution Load Index (PLI) - calculated with equation 4, indicated the total degree of contamination and demonstrates deterioration of the conditions due to the accumulation of heavy metals in surface sediments [16-17]:

$$
P L I=\left(P I_{1} \times \ldots \times P I_{i}\right)^{1 / n}
$$

where:

$P I_{1 \ldots i}$ - pollution index for each metal $\mathrm{i}$; $\mathrm{n}$ - number of metals taken into consideration (for this study $\mathrm{n}=5$ ).

In Table 7 the interpretation of the contamination categories of the pollution load index is presented.

Table 7. Contamination categories of Pollution Load Index (PLI) [16-17]:

\begin{tabular}{|c|c|}
\hline Value of $\boldsymbol{P L I}$ & Pollution status \\
\hline$<1$ & denote perfection \\
\hline 1 & between the acceptable limits of pollution \\
\hline$>1$ & deterioration of soil quality \\
\hline
\end{tabular}

The source (natural or anthropogenic) of heavy metals was identified after calculating the multi-element contamination (MEC) index [16] [20]. This is a measure of contamination assessment on the surface sediment with the tolerable levels given. It was calculated with equation 5 :

$$
M E C=\frac{\left(\frac{C_{1}}{T_{1}}+\cdots+\frac{C_{i}}{T_{i}}\right)}{n}
$$

where:

$C_{1 \ldots i}$ - content of the heavy metal;

$T_{i}$ - tolerable levels 
Higher values than 1 of the MEC index certify the presence of the anthropogenic impact in the analyzed surface sediments.

According to Hakanson, (2011) [20], the Potential Ecological Risk (RI) was calculated for assessing the degree of the ecological risk related to the presence of the heavy metals in analyzed surface sediment. The calculation of this index was in accordance with equation 6 and 7 [20].

$$
R I=\sum_{i=1}^{n} E_{f}^{i}
$$

where: $R I$ - pollution index; $E_{f}^{i}$ - pollution coefficient of a single metal. equation:

The pollution coefficient of a single metal was calculated with the

$$
E_{f}^{i}=T_{f}^{i} \times P I_{i}
$$

where:

$E_{f}^{i}$ - pollution coefficient of a single metal;

$T_{f}^{i}$ - factor of the biological (surface benthic) toxicity for each metal: As=10, $\mathrm{Cd}=30, \mathrm{Cu}=\mathrm{Pb}=5$ and $\mathrm{Zn}=2$, all in $\mathrm{mg} \mathrm{kg}^{-1}$ dry weight [24] $P I_{i}$ - pollution index for each metal, calculated with equation 1.

Applying these calculations was possible to highlight the level of pollution based on data presented by Kowalska, 2018 [16]: <90 - low pollution ecological risk, 90-180 - moderate pollution ecological risk, 180360 strong pollution ecological risk, $360-720$ very strong pollution ecological risk, $\geq 720$ highly-strong pollution ecological risk.

\section{Chemical analysis}

Metal concentrations in water and sediment samples were analyzed using graphite furnace atomic absorption spectrometry (GF-AAS) and comprised of two stages: sample digestion, and quantitative analysis of metals in digested samples using a Perkin-Elmer AAS, type AAnalyst 700, metrological verified and provided with a calibration certificate.

Each result was obtained as an average of three individual sample readings and validated using relative standard deviation, using the software WinChemLab. The calibration curves used were validated based on the determination coefficient $\left(R^{2}\right)$, only values of $\geq 0,990$ being accepted. For each processed samples batch, in lab, was run a blank sample consisting in 
ultrapure water, sample for intern control: Shewhart diagrams, replicated and CRM (for water sample: TM-24.4 - „A low level fortified sample for trace elements", Environment and Climate Change Canada; for sediments: BCR320R „Channel sediment (trace element)”, LGC-Standards). The measured mean and standard deviation of elemental values for CRM were compared with the certified values. In both cases it was confirmed that the sample preparation and instrumentation conditions provided good levels of accuracy, precision and degree of recovery (90-110\%).

Samples digestion was performed in Teflon vessels of a microwave digestion system, Millestone Ethos $D$, according to producer operating instructions, namely DG-EN-30 and DG-EN-08 for sediment and water, respectively. Thus, $0.2 \mathrm{~g}$ dried sediment sample were digested with acids (4 $\mathrm{ml}$ of $96 \% \mathrm{H}_{2} \mathrm{SO}_{4}$ in the first step, then in second step, $6 \mathrm{ml}$ of $65 \% \mathrm{HNO}_{3}$, analytical purity, provided by Merck, Darmstadt, Germany), at $220{ }^{\circ} \mathrm{C}, 20$ minutes, at $800 \mathrm{~W}$ microwave power [25].

The residue obtained after mineralization was brought into $50 \mathrm{ml}$ volumetric flasks with $0.02 \mathrm{M} \mathrm{HNO}_{3}$ solution, which, after filtration, subjected to metal determination using GF-AAS technique.

\section{REFERENCES}

1. C. Sofronie, Amenajări Hidrotehnice în Bazinul Hidrografic Someș-Tisa, Gloria Home Press, Cluj-Napoca, Romania, 2000, pp. 20-65.

2. D.L. Ciurte, A. Mihu-Pintilie, L.E. Paveluc, C.C. Stoleriu, Proceeding of the $5^{T H}$ Jubilee International Scientific Conference \& Expo, Geobalcanica (13-14 June 2019, Sofia, Bulgaria), 2019, 591-597.

3. M. Deng, X. Yang, X. Dai, Q. Zhang, A. Malik, A. Sadeghpour, Ecol. Indic., 2020, 112, 106-166.

4. M. Kijowska-Strugala, L. Wiejaczka, R. Kozlowski, J. Lekach, Int. J. Sediment Res., 2020, 35, 269-277.

5. H. Bing, J. Zhou, Y. Wu, X. Wang, H. Sun, R. Li, Environ. Pollut., 2016, 214 , 485-496.

6. P. Palma, L. Ledo, P. Alvarenga, Catena (Amst), 2015, 128, 174-184.

7. A. Zahra, M.Z. Hashmi, R.N. Malik, Z. Ahmed, Sci. Total Environ., 2014, 470471, 925-933.

8. L. Zhao, D. Gong, W. Zhao, L. Lin, W. Yang, W. Guo, X. Tang, Q. Li, Sci. Total Environ., 2020, 704, 134883.

9. A. Pratap, F.S. Mani, S. Prasad, Mar. Pollut. Bull., 2020, 156, 111238.

10. Z. Zhou, T. Huang, Y. Li, W. Ma, S. Zhou, S. Long, J Environ Sci (China), 2017, 52, 223-231. 
RESEARCH ON THE HEAVY METALS IN SURFACE SEDIMENTS,

IN STRÂMTORI-FIRIZA RESERVOIR, SITUATED IN N-W OF ROMANIA

11. Order no. $161 / 2006$ for the approval of Normative on the surface water classification in view of establishing ecological status of water bodies, published in OG no. 511/13 June 2006.

12. SR EN ISO 5667-6:2017 - Water quality - Sampling - Part 6: Guidance on sampling of rivers and streams.

13. SR ISO 5667-12:2001 - Water quality. Sampling. Part 12: Guidance on sampling of bottom sediments.

14. SR EN ISO 5667-15:2010 - Water quality. Sampling. Part 15: Guidance on preservation and handling of sludge and sediment samples.

15. A. Cernatoni, V. Cușa, Institute of Research and Environmental Engineering, Ministry of Waters, Forests and Environmental Protection Press, Romania, 1996, pp. 40-52.

16. J.B. Kowalska, R. Mazurek, M. Gasiorek, T. Zaleski, Environ. Geochem. Health, 2018, 40, 2395-2420.

17. M. Varol, J. Hazard. Mater., 2011, 195, 355-364.

18. S.A. El-Sayed, E.M.M. Moussa, M.E.I El-Sabagh, J. Radiat. Res. Appl. Sci., 2015, 8, 276-285.

19. M.E. Goher, H.I. Farhat, M.H. Abdo, S.G. Salem, Egypt J Aquat Res, 2014, 40, 213-224.

20. L. Håkanson, Water Res., 2011, 14, 975 - 1001.

21. G. Müller, Veränderungen seit, 1979, 1971, 107-126.

22. U. Förstner, W. Ahlf, W. Calmano, M. Kersten,1990, Sediment Criteria Development. In: Heling D., Rothe P., Förstner U., Stoffers P. (eds) Sediments and Environmental Geochemistry. Springer, Berlin, Heidelberg. https://doi.org/10.1007/978-3-642-75097-7_18.

23. M. Singh, A.A. Ansari, G. Müller, et al., Environ. Geol., 2013, 29 (3/4), 246-252.

24. A. Kloke, Tolerable amount of heavy metals in soil and their accumulation in plants, Environmental Effects of Organic and Inorganic Contaminants in Sewage Sludge Press, 1983, 171-175.

25. DG-EN-30 protocol. Technical Book DIGESTOR (microwaves oven) Milestone. type ETHOS - Application: Environment - River sediment. Digestion Application Note: DG-EN-30. Rev. 03_04. 